\title{
Padrões insustentáveis de consumo: um panorama do desequilíbrio global nos hábitos individuais e suas consequências para o Desenvolvimento Sustentável
}

\author{
Aline Eggres de Castro \\ Universidade Federal de Santa Maria \\ Marcelo Trevisan \\ Universidade Federal de Santa Maria
}

\section{RESUMO}

\begin{abstract}
Hábitos ostensivos de consumo têm se consolidado nos debates sobre o Desenvolvimento Sustentável como um dos principais causadores da crise ambiental enfrentada pelo planeta. O estudo tem por objetivo debater os temas relacionados aos hábitos de consumo excessivos praticados por populações economicamente favorecidas - especialmente pertencentes aos países desenvolvidos do hemisfério norte -, em contraste com o consumo insuficiente ao qual grande parte da população mundial - principalmente dos países em desenvolvimento do hemisfério sul - é submetida devido à falta de acesso aos recursos. Para tanto, foi revisado o estado da arte relacionado às temáticas do Desenvolvimento Sustentável, padrões insustentáveis de consumo (consumo excessivo nas classes médias e altas e consumo insuficiente na base da pirâmide) e estratégias de mudanças nos hábitos de consumo - consumo verde, consumo consciente e consumo sustentável. Tais conceitos muitas vezes são confundidos ou até mesmo utilizados como sinônimos na literatura, sem especificar uma diferenciação clara entre eles. Para esse estudo buscou-se um significado mais profundo para cada termo, a fim de compreender melhor a evolução do pensamento social relacionado aos hábitos de consumo e o papel do consumidor nesse processo. Com isso, foram feitos vínculos entre os temas e os resultados das análises evidenciaram que os hábitos excessivos têm consequências diretas na degradação ambiental e social as quais as populações desfavorecidas são submetidas. Para reverter esse quadro é fundamental uma mudança de hábitos que inclua o pensamento coletivo nas decisões individuais.
\end{abstract}

Palavras-chave: Desenvolvimento Sustentável; consumo excessivo; desequilíbrio; base da pirâmide.

\begin{abstract}
Ostentatious consumption habits have been established in the debate on sustainable development as a major cause of the environmental crisis that the planet is facing. This study aims to discuss issues related to excessive consumption habits practiced by economically privileged populations - especially those from developed northern countries - in contrast to the insufficient consumption to which much of the world's population - mostly in developing countries of the southern hemisphere - is subjugated due to the lack of access to resources. To do this, the literature related to the themes of sustainable development, unsustainable patterns of consumption (overconsumption in the middle and upper classes and insufficient consumption in the bottom of the pyramid) and strategies on changes in consumer habits (green consumption, conscious consumption and sustainable consumption) was reviewed. Such concepts are often confused or even used as synonyms in the literature, without specifying a clear differentiation between them. In this study, a deeper meaning for each term was sought, in order to better understand the evolution of social thinking related to consumption habits and the role of the consumer in this process. With that, links among themes were made and the findings showed that excessive habits have direct consequences on environmental and social degradation in which disadvantaged populations are subjugated. To reverse this situation a change in habits is essential to include the collective thinking on individual decisions.
\end{abstract}

Keywords: Sustainable Development; excessive consumption; imbalance; base of the pyramid. 


\section{INTRODUÇÃO}

Os processos de degradação de nosso planeta, relacionados a hábitos de consumo insustentáveis, e o desequilíbrio entre a utilização de riqueza produzida e o acesso aos recursos, traz a reflexão sobre o papel de cada um de nós para tentar reverter esse caminho. As ações governamentais, empresariais e os avanços da ciência e tecnologia não são suficientes para barrar os danos que já foram e continuam sendo causados - tais ações precisam vir aliadas da mudança no comportamento de toda a sociedade. É preciso conscientizar as pessoas de que suas condutas têm consequências globais, gerando um impacto real na mudança de atitudes. Essa conscientização é um processo evolutivo que tem ganhado notoriedade à medida que os estudos sobre o Desenvolvimento Sustentável alcançam legitimidade.

Barbieri e Silva (2011) apontam que a partir da publicação do relatório "Nosso Futuro Comum", produzido pela Comissão Mundial sobre Meio Ambiente e Desenvolvimento, a expressão Desenvolvimento Sustentável passou a ser difundida, tornando-se popular, com a Conferência das Nações Unidas para o Desenvolvimento e Meio Ambiente, realizada no Rio de Janeiro, em 1992 (conhecida como "Rio-92"). Um dos principais guias gerados por esses encontros de líderes mundiais é a Agenda 21, documento aprovado na Rio-92, que consiste em um programa de ação abrangente para orientar a humanidade em direção a um desenvolvimento que seja ao mesmo tempo socialmente justo e ambientalmente sustentável. A Agenda 21 é constituída por 40 capítulos, dedicados às diversas questões sociais e ambientais de caráter planetário (erradicação da pobreza, proteção da atmosfera, conservação da biodiversidade, etc.).

Por ser muito abrangente, a questão do consumo é tratada em diversos pontos da Agenda 21, mas recebe especial atenção no Capítulo 4, cujo tema trata da mudança dos padrões de consumo. O foco está no exame dos padrões insustentáveis de produção e consumo; e no desenvolvimento de políticas e estratégias de estímulo a mudanças nos padrões insustentáveis de consumo. A existência desse capítulo na Agenda 21 evidencia que já na Rio-92 discutia-se a questão do consumo como uma das causas centrais dos problemas ambientais. Ainda nessa conferência, houve a tentativa por parte da ONU da realização de outro documento, chamado "Carta da Terra", mas que não obteve consenso em sua elaboração naquele momento (MMA, 2018).

Um primeiro esboço da Carta da Terra foi realizado, pela sociedade civil, de forma independente, somente em 1997 sob a coordenação de Maurice Strong (ONU) e Mikhail Gorbachev (Cruz Verde Internacional). Em 1999, Steven Rockfeller escreveu o segundo esboço que foi ratificado e amplamente divulgado em 2000. A Carta da Terra é uma declaração de princípios éticos voltados para a construção de uma sociedade global justa, sustentável e pacífica, que visa a inspirar o senso de responsabilidade compartilhada nos povos. A situação global, conforme descrita pela Carta da Terra, exige atenção de toda a população. O documento enfatiza que os padrões dominantes de produção e consumo estão causando devastação ambiental, redução dos recursos e uma massiva extinção de espécies. Comunidades estão sendo arruinadas. Os benefícios do desenvolvimento não estão sendo divididos equitativamente e o fosso entre ricos e pobres está aumentando. A injustiça, a pobreza, a ignorância e os conflitos violentos têm aumentado e são causa de grande sofrimento. O crescimento sem precedentes da população humana tem sobrecarregado os sistemas ecológico e social. As bases da segurança global estão ameaçadas (MMA, 2018).

Ainda mais recente que esses compromissos é a 'Agenda 2030 para o Desenvolvimento Sustentável', contendo 17 objetivos de Desenvolvimento Sustentável e 169 metas, criada pela ONU em 2015, envolvendo 193 estados membros. Nestes objetivos e metas, a ONU estabelece uma visão ambiciosa e transformadora que prevê um mundo livre da pobreza, fome, doença e penúria, onde toda a vida pode prosperar. Diversos desses objetivos estão diretamente relacionados com o poder de consumo de sociedades menos favorecidas - como "acabar com a pobreza em todas as suas formas, em todos os lugares"; "acabar com a fome, alcançar a segurança alimentar e melhoria da nutrição"; "assegurar a disponibilidade e gestão 
sustentável da água e saneamento para todos"; "assegurar o acesso confiável, sustentável, moderno e a preço acessível à energia para todos", "assegurar padrões de produção e de consumo sustentáveis" (ONU, 2018), entre outros objetivos que direta ou indiretamente visam a permitir que todas as pessoas, independente de sua classe social, tenham condições mínimas de uma vida digna por meio do acesso a alimentação, saúde, educação e infraestrutura. Mor se et al. (2018) acreditam que para alcançar os Objetivos de Desenvolvimento Sustentável da ONU, é imprescindível que populações mais pobres atinjam níveis de consumo básicos, como a segurança alimentar.

Dados apresentados nesse estudo evidenciam que hábitos de consumo individuais tem grande impacto ambiental e podem ter consequências globais. Isso mostra a importância da consciência e responsabilização de cada um pelo seu impacto no meio ambiente e pela necessidade de mudanças de hábitos a fim de buscar um planeta mais sustentável e com distribuição mais justa de recursos.

Este estudo, de cunho teórico, tem por objetivo debater os temas relacionados aos hábitos de consumo excessivos praticados por populações economicamente favorecidas especialmente pertencentes aos países desenvolvidos do hemisfério norte -, em contraste com o consumo insuficiente ao qual grande parte da população mundial - principalmente dos países em desenvolvimento do hemisfério sul - é submetida devido à falta de acesso aos recursos. O estudo pretende associar as questões relacionadas à emergência do Desenvolvimento Sustentável com os padrões de consumo insustentáveis da sociedade. Esse é um tema de extrema relevância, mas tão cuidadosamente abordado dentro dos estudos de Administração, visto que ao tratar sobre redução de padrões de consumo entra-se em conflito direto com os interesses econômicos dominantes.

Para enfrentar o problema, outro objetivo do estudo é apresentar estratégias de mudanças nos padrões de consumo e esclarecer as diferenças entre as estratégias encontradas na literatura, que muitas vezes são confundidas ou até mesmo utilizadas como sinônimos consumo verde, consumo consciente e consumo sustentável. A emergência da degradação ambiental justifica a relevância desse estudo e enfatiza a importância de quebrar essas barreiras e enfrentar o problema de forma direta, contribuindo para que os principais atores envolvidos - empresas, governos, consumidores - assumam a sua responsabilidade no processo de mudança.

Por meio de uma revisão bibliográfica sobre os temas do Desenvolvimento Sustentável, padrões insustentáveis de consumo (consumo excessivo nas classes médias e altas e consumo insuficiente na base da pirâmide) e estratégias de mudanças nos hábitos de consumo (consumo verde, consumo consciente e consumo sustentável), além da consulta em relatórios oficiais de órgãos especializados, fizeram-se associações entre os temas e conclusões a respeito do reflexo que as questões trazem para o futuro do planeta. O método utilizado foi uma revisão bibliográfica da literatura publicada sobre o assunto estudado e as conclusões foram elaboradas por meio de interpretação, que procurou dar um significado mais amplo às informações encontradas (MARCONI; LAKATOS, 2017).

\section{O CONTROVERSO CONCEITO DE DESENVOLVIMENTO SUSTENTÁVEL}

O desenvolvimento sustentável é um tema em constante construção, visto que diversos autores, como os citados a seguir, divergem sobre o real significado que o termo carrega consigo. O conceito mais tradicional de Desenvolvimento Sustentável é o apresentado pela ONU em 1987, elaborado pela World Commission on Environment and Development (WCED): "satisfazer as necessidades do presente sem comprometer a capacidade de as futuras gerações satisfazerem suas próprias necessidades" (WCED, 1987, p.43). A definição gera debates, no entanto, visto que muitos dos ideais da sustentabilidade estariam mais voltados à contenção de necessidades e não à plena satisfação de tudo aquilo que o homem deseja. O próprio termo 'desenvolvimento' pode ser considerado contraditório à sustentabilidade, já que exige a exploração de recursos. Castro et al. (2018) questionam se "é possível 'desenvolvimento' ser 'sustentável'?" visto que para Robinson (2004), crescimento e desenvolvimento seriam imperativos opostos de uma ideia de Sustentabilidade ecológica (e talvez social e econômica), portanto o termo 'Desenvolvimento Sustentável' seria contraditório.

$\mathrm{Na}$ percepção de Dias et al. (2003) a definição estabelecida pela WCED implica que o 
desenvolvimento sustentável procura estabelecer uma relação harmônica do homem com a natureza, como centro de um processo de desenvolvimento que deve satisfazer as necessidades e as aspirações humanas. Enfatiza que a pobreza é incompatível com o desenvolvimento sustentável e indica a necessidade de que a política ambiental deve ser parte integrante do processo de desenvolvimento e não mais uma responsabilidade setorial fragmentada.

De acordo com Romeiro (2003) o conceito de Desenvolvimento Sustentável surgiu para amenizar a controvérsia entre as relações de crescimento econômico e meio ambiente, exacerbada pela publicação do relatório do Clube de Roma que pregava o crescimento zero como forma de evitar a catástrofe ambiental. O conceito, na visão de Romeiro (2003), emerge, portanto, desse contexto como uma proposição conciliadora, em que se reconhece que o progresso técnico efetivamente relativiza os limites ambientais, mas não os elimina, e que o crescimento econômico é condição necessária, mas não suficiente para a eliminação da pobreza e das desigualdades sociais.

Atualmente a abordagem mais utilizada para tratar do assunto é a que engloba três dimensões da sustentabilidade que servem como pilares que ditam o caminho do desenvolvimento: social (qualidade de vida, educação, saúde, saneamento, igualdade, oportunidades, desenvolvimento comunitário); ambiental (conservação da natureza, aproveitamento energético, políticas e código ambiental, prevenção de poluição, redução de resíduos no ar, água e solo); e econômica (lucratividade, redução de suprimentos e custos, crescimento, ciência, tecnologia e inovação) (ELKINGTON, 2012). Lélé (1991) aponta que temas relacionados ao Desenvolvimento Sustentável se tornaram uma série de "consertos", visando estratégias e mudanças tecnológicas para reduzir impactos, criar políticas econômicas que incorporam considerações ambientais e diversas outras práticas que tentam corrigir erros das gerações anteriores que causaram problemas profundos.

Leal Filho et al. (2017) apontam que embora o conceito básico de sustentabilidade remonte a muitos séculos, só recentemente ele apareceu na agenda política internacional. Isso se deve em parte ao despertar do fato de que a pressão ecológica humana no planeta ainda é muito maior do que a natureza pode renovar ou compensar. Essa preocupação internacional foi enfatizada pelo estabelecimento dos objetivos para o Desenvolvimento Sustentável da ONU. Para Leal Filho et al. (2017), esses objetivos devem revigorar a pesquisa sobre Desenvolvimento Sustentável, visto que o fato de que a ONU e seus países membros se comprometeram a alcançar os objetivos até 2030 acrescentou um senso de urgência à necessidade de realizar pesquisas de qualidade sobre o tema e reitera a necessidade de utilizar os resultados desta pesquisa na prática.

Glavic e Lukman (2007) acreditam que o desenvolvimento sustentável é um processo no qual é enfatizada a evolução da sociedade humana a partir do ponto de vista economicamente responsável, em acordo com o meio ambiente. É uma linha do tempo, onde princípios, abordagens, estratégias e políticas podem ajudar a desenvolver e implementar uma visão de futuro de uma sociedade sustentável, a qual irá exigir padrões de pensamento diferentes e mudanças no estilo de vida.

O conceito, portanto, encontra-se em constante evolução, em um estado de diálogo permanente, visto que a busca por uma definição mais clara e precisa é importante para legitimar o tema na sociedade. A crescente conscientização a respeito de temas como o esgotamento dos recursos naturais e da capacidade da biosfera em absorver resíduos e poluentes, por exemplo, contribuem tanto para o enriquecimento da teoria, quanto para o engajamento social para ações que busquem melhorias a longo prazo. Kolk (2016) aponta que entre os temas que contornam o Desenvolvimento Sustentável, um dos mais discutidos até agora, desde a década de 1960, foi a pobreza e o desenvolvimento, incluindo a diferença de renda entre nações ricas e pobres e o problema alimentar mundial. A seguir é discutida a questão dos padrões de consumo que impulsionaram essas diferenças entre países ricos e pobres.

\section{PADRÕES INSUSTENTÁVEIS DE CONSUMO}

A crise ambiental, segundo Portilho (2005), era atribuída até a década de 1970 ao 
crescimento demográfico, principalmente, nos países em desenvolvimento, que provocaria uma grande pressão humana sobre os recursos naturais do planeta. Com a realização da Conferência de Estocolmo (Conferência das Nações Unidas sobre o Meio Ambiente Humano) em 1972, os países em desenvolvimento tornaram explícito o argumento de que, na realidade, os principais responsáveis pela crise ambiental eram as nações industrializadas, que pelo se $u$ modo de produção, eram os maiores consumidores de recursos e energia do planeta e os maiores poluidores. Essa nova argumentação estimulou um primeiro deslocamento do debate ambiental do crescimento populacional nos países do Sul para os padrões de produção dos países do Norte ocidental. Isso iniciou um processo de internalização da pauta ambiental nos meios de produção, seja por pressão governamental (pelo estabelecimento de novas normas e exigências ambientais), por pressão dos movimentos ambientalistas (por meio de denúncias, manifestações e boicotes) ou ainda por iniciativa dos próprios empresários que se apropriaram do discurso ambiental.

As negociações preliminares nos preparativos para a Rio-92 envolveram controvertidos debates sobre a relação entre estilo de vida e práticas de consumo e problemas ambientais globais. Os documentos produzidos durante a conferência, especialmente a Agenda 21, a Declaração do Rio e o Tratado das ONGs, começaram a apontar a responsabilidade pela crise ambiental aos estilos de vida e consumo, principalmente das populações dos países do Norte, que viviam uma sociedade pós-industrial, onde o lazer e o consumo se tornaram atividades fundamentais. Assim, o nível e o estilo de consumo se tornam a principal fonte de identidade cultural e de participação na vida coletiva. Isso acarretou uma segunda mudança no discurso dominante sobre os problemas ambientais, cujo foco passou da produção para o consumo (PORTILHO, 2005).

O Capítulo 4 da Agenda 21, que trata das mudanças dos padrões de consumo, aponta que como parte das medidas a serem adotadas no plano internacional para a proteção e a melhora do meio ambiente é necessário levar plenamente em conta os atuais desequilíbrios nos padrões mundiais de consumo e produção. Isso se dá porque a pobreza e a degradação do meio ambiente estão estreitamente relacionadas. Enquanto a pobreza tem como resultado determinados tipos de pressão ambiental (em função da falta de estrutura), as principais causas da deterioração ininterrupta do meio ambiente mundial são os padrões insustentáveis de consumo e produção, especialmente nos países industrializados. Motivo de séria preocupação, tais padrões de consumo e produção provocam o agravamento da pobreza e dos desequilíbrios.

Cheng et al. (2018) apontam que há pouca pesquisa sobre a vinculação entre ecologia, meio ambiente e pobreza e como essa relação influencia no Desenvolvimento Sustentável. Para os autores, a degradação ecológica e ambiental e a pobreza estão ligadas e devem ser enfrentadas em conjunto. Estratégias 'ganha-ganha' nos níveis local e nacional que restauram o meio ambiente, aumentam a renda e asseguram uma subsistência sustentável são necessárias. Cushing et al. (2015) pesquisaram evidências de uma relação entre a qualidade ambiental e a desigualdade social ao longo dos eixos de renda, riqueza, poder político e raça e etnia. O estudo sugere que sociedades mais desiguais têm ambientes mais poluídos e degradados, talvez ajudando a explicar por que sociedades mais desiguais são menos saudáveis.

O capítulo 4 da Agenda 21 ainda aponta que embora em determinadas partes do mundo os padrões de consumo sejam muito altos, as necessidades básicas do consumidor de um amplo segmento da humanidade não estão sendo atendidas. Isso se traduz em demanda excessiva e estilos de vida insustentáveis nos segmentos mais ricos, que exercem imensas pressões sobre o meio ambiente. Enquanto isso os segmentos mais pobres não têm condições de ser atendidos em suas necessidades de alimentação, saúde, moradia e educação. A mudança dos padrões de consumo exigirá uma estratégia multifacetada centrada na demanda, no atendimento das necessidades básicas dos pobres e na redução do desperdício e do uso de recursos finitos no processo de produção.

As diferenças nos padrões globais de consumo são evidentes, visto que $20 \%$ da população mundial, que habita principalmente os países afluentes do hemisfério norte, consome $80 \%$ dos recursos naturais e energia do planeta e produz mais de $80 \%$ da poluição e da degradação dos ecossistemas. Enquanto isso, $80 \%$ da população mundial, que habita principalmente os países pobres do hemisfério sul, fica com apenas $20 \%$ dos recursos naturais. Para reduzir essas 
disparidades sociais, permitindo aos habitantes dos países do sul atingirem o mesmo padrão de consumo material médio de um habitante do norte, seriam necessários, pelo menos, mais dois planetas Terra (MMA/MEC/IDEC, 2005).

Cortez (2009) afirma que há evidências de que o padrão de consumo das sociedades ocidentais modernas, além de ser socialmente injusto e moralmente indefensável, é ambientalmente insustentável. A crise ambiental mostrou que não é possível a incorporação de todos no universo de consumo em função da finitude dos recursos naturais. $\mathrm{O}$ ambiente natural está sofrendo uma exploração excessiva que ameaça a estabilidade dos seus sistemas de sustentação: exaustão de recursos naturais renováveis e não-renováveis, degradação do solo, perda de florestas e da biodiversidade, poluição da água e do ar e mudanças climáticas, entre outros. E o resultado dessa exploração excessiva não é dividido igualmente para todos, apenas uma minoria da população da Terra se beneficia dessa riqueza.

Se considerado o princípio ético de que todos os habitantes do planeta (das presentes e das futuras gerações) têm o mesmo direito a usufruir dos recursos naturais e dos serviços ambientais disponíveis, enquanto os países desenvolvidos continuarem a promover uma distribuição desigual dos recursos naturais, os países pobres poderão continuar reivindicando o mesmo nível elevado neste uso, tornando impossível a contenção do consumo global dentro de limites sustentáveis. Neste contexto, os riscos de conflitos por recursos naturais, a fome, migrações internacionais e refugiados ecológicos tenderão a aumentar. Tal dilema aponta para a percepção ética de que todos os povos devem ter direitos proporcionais no acesso e utilização dos recursos naturais. Assim, para reduzir a disparidade social e econômica, seria necessário tanto um piso mínimo quanto um teto máximo de consumo. Porém, cada povo tem o direito e o dever de estabelecer padrões próprios de estilo de vida e consumo, não necessariamente copiando os estilos de vida de outras culturas (CORTEZ, 2009).

Lançado a cada dois anos pela Rede WWF, o "Relatório Planeta Vivo" é, segundo o próprio relatório, a mais importante análise baseada na ciência sobre a saúde do planeta e apresenta um cenário detalhado e atualizado da situação do meio ambiente. A edição 2018 aponta que a combinação de perda de biodiversidade e Pegada Ecológica ${ }^{1}$ insustentável ameaça os sistemas naturais e o bem-estar humano no mundo todo. A exploração excessiva e a atividade agrícola, impulsionadas pelo consumo descontrolado, ainda são as causas dominantes da perda atual de espécies - a degradação da terra afeta seriamente $75 \%$ dos ecossistemas terrestres, reduzindo o bem-estar de mais de 3 bilhões de pessoas, com enormes custos econômicos.

A explosão do consumo humano é a força motriz por trás da mudança planetária sem precedentes que estamos testemunhando, através da crescente demanda por energia, terra e água. Os indicadores de consumo - como a Pegada Ecológica - fornecem uma imagem do uso geral dos recursos. Os produtos que consumimos, as cadeias de suprimentos por trás deles, os materiais que eles usam e como estes são extraídos e fabricados têm uma miríade de impactos no mundo ao nosso redor (WWF, 2018).

Além do excesso de consumo, o relatório da Rede WWF (2018) aponta que os recursos naturais estão distribuídos de forma desigual pela Terra. O padrão de consumo humano desses recursos difere da disponibilidade de recursos, uma vez que os recursos não são consumidos no ponto de extração. Observar a Pegada Ecológica de cada pessoa em nível nacional fornece informações adicionais sobre onde os recursos do mundo estão sendo consumidos. Os níveis variados da Pegada Ecológica são devidos a diferentes estilos de vida e padrões de consumo, incluindo a quantidade de alimentos, bens e serviços consumidos pelos residentes, os recursos naturais que eles usam e o dióxido de carbono emitido para fornecer esses bens e serviços. A imagem a seguir demonstra a distribuição da pegada ecológica pelo planeta, medida em unidades padrão chamadas "hectares globais". Um hectare global é a quantidade anual mundial de produção biológica para uso humano e assimilação de lixo humano, por hectare de terra e pesca biologicamente produtivas (WWF, 2018).

Figura 1 - Mapa global da pegada ecológica do consumo

\footnotetext{
${ }^{1}$ Pegada Ecológica é a quantidade de recursos naturais renováveis para manter o estilo de vida de uma pessoa. A Pegada Ecológica Total de um país é uma função da população total e das taxas de consumo - o consumo de um país inclui a Pegada Ecológica que produz, mais as importações de outros países, menos as exportações.
} 


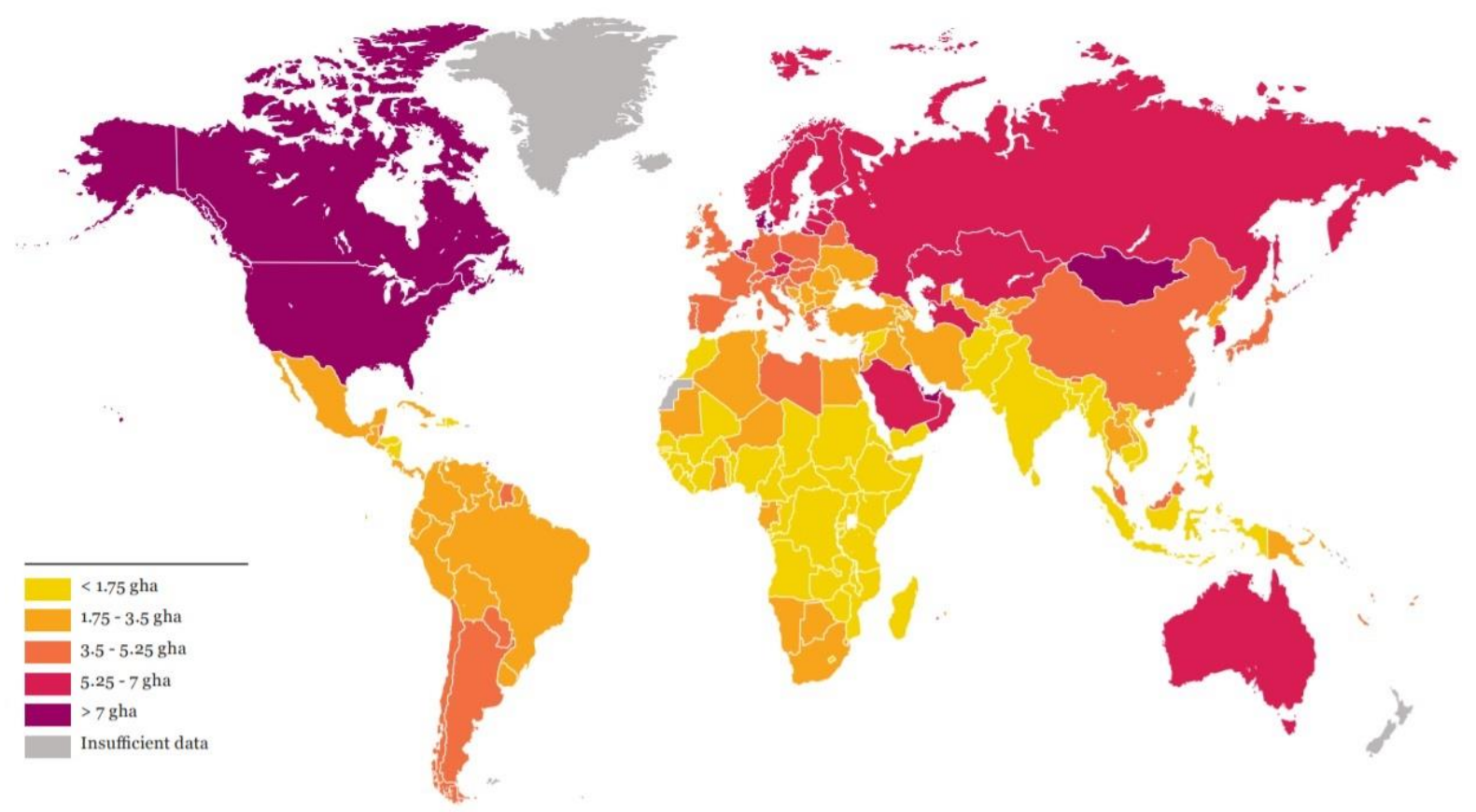

Fonte: Relatório Planeta Vivo, WWF (2018)

A imagem deixa claro os padrões desproporcionais de consumo entre os hemisférios nortes e suis do planeta, como níveis quase cinco vezes maiores de consumo dos EUA em relação a países africanos, por exemplo. Além da rede WWF, os dados do Carbon Dioxide Information Analysis Center - Centro de Análise de Informações de Dióxido de Carbono (CDIAC) apresentados no Quadro 1 corroboram essas discrepâncias. A organização disponibiliza um ranking dos países do mundo até 2014 (relatório mais recente disponível) quanto às emissões totais de $\mathrm{CO} 2$ - da queima de combustíveis fósseis, produção de cimento e queima de gás. As emissões (CO2_TOT) são expressas em mil toneladas métricas de Carbono. O quadro 1 demonstra os 10 países que mais poluem até o ano de 2014. Quanto aos países que menos poluem há uma discrepância bastante elevada, visto que enquanto as emissões das nações mais poluentes chegam nas casas dos milhões, as menos poluentes não passam de dezenas ou centenas de toneladas métricas de Carbono - as quatro nações menos poluentes (Ilhas Wallis e Futuna, Santa Helena, Niue e Tuvalu) possuem apenas unidades. Resguardadas as diferenças de proporções populacionais e territoriais, é evidente ao observar a lista completa (disponível no web site da CDIAC) que os países ricos do hemisfério norte encontram-se entre os mais poluentes, enquanto os países pobres do hemisfério sul, especialmente países do continente africano, mesmo aqueles com grandes territórios e populações, apresentam baixo impacto nos níveis de emissão de gases. 
Quadro 1 - Ranking dos países do mundo até 2014 quanto às emissões totais de CO2

\begin{tabular}{|c|c|c|}
\hline $\begin{array}{l}\text { Posição no } \\
\text { ranking }\end{array}$ & Nação & CO2_TOT \\
\hline 1 & China & 2.806 .634 \\
\hline 2 & $\begin{array}{c}\text { Estados Unidos da } \\
\text { América }\end{array}$ & 1.432 .855 \\
\hline 3 & Índia & 610.411 \\
\hline 4 & Federação Russa & 465.052 \\
\hline 5 & Japão & 331.074 \\
\hline 6 & Alemanha & 196.314 \\
\hline 7 & $\begin{array}{c}\text { República Islâmica } \\
\text { do Irão }\end{array}$ & 177.115 \\
\hline 8 & Arábia Saudita & 163.907 \\
\hline 9 & República da Coréia & 160.119 \\
\hline 10 & Canadá & 146.494 \\
\hline
\end{tabular}

Fonte: CDIAC (Carbon Dioxide Information Analysis Center - Centro de Análise de Informações de Dióxido de Carbono

Outro fator que deve ser levado em consideração quando se fala de níveis desiguais de consumo é o índice de desigualdade social dentro dos países. Um país onde há maior concentração de riquezas faz com que grande parcela da população que não tem acesso a esses recursos fique excluída da sociedade de consumo. Para medir os índices de concentração de riqueza existe um índice chamado de Coeficiente GINI, que consiste na medida do desvio da distribuição de renda entre indivíduos ou famílias dentro de um país a partir de uma distribuição perfeitamente igual. Um valor de 0 representa igualdade absoluta, um valor de 100 desigualdade absoluta (PNUD, 2016).

Utilizando dados do coeficiente GINI e do IDH (índice de desenvolvimento humano), o Relatório de Desenvolvimento Humano de 2016 publicado pelo Programa das Nações Unidas para o Desenvolvimento (PNUD) criou o 'Índice de desenvolvimento humano ajustado à desigualdade'. Entre os dez países com menor índice de desigualdade e muito alto desenvolvimento humano estão: Noruega, Austrália, Suíça, Alemanha, Dinamarca, Singapura, Holanda, Irlanda, Islândia e Canadá - majoritariamente países ricos do hemisfério norte. Já entre os dez países com maior desigualdade e muito baixo desenvolvimento humano estão: Eritreia, Serra Leoa, Moçambique, Sudão do Sul, Guiné, Burundi, Burkina Faso, Chade, Níger e República Centro-Africana - todos países africanos pobres do hemisfério sul.

Tal desigualdade está diretamente relacionada aos índices de Desenvolvimento Sustentável, visto que o mesmo relatório ranqueia os países mais e menos desenvolvidos neste quesito e os países mencionados no ranking anterior encontram-se exatamente nas mesmas posições nos dois diferentes índices. Para medir o índice de Desenvolvimento Sustentável, o PNUD utiliza os seguintes critérios: consumo de energia renovável, emissões de dióxido de 
carbono, área florestal, escassez de água limpa, esgotamento de recursos naturais, ajustamento de economias, dívida externa, despesas com pesquisa e desenvolvimento, índice de concentração de exportações, renda, desigualdade de gênero, população na pobreza multidimensional e nível de dependência dos idosos.

Além disso, os níveis desiguais de consumo também afetam os países mais pobres em função da destinação do lixo dos países mais consumistas. Grant e Oteng-Ababio (2012) apontam que o lixo eletrônico, por exemplo, é uma indústria de mais de US $\$ 7$ bilhões e as remessas transfronteiriças desse lixo ocorrem em circuitos internacionais, normalmente originários dos Estados Unidos e da Europa, mas agora também da China, e se conectam a locais de acumulação em cidades particularmente na África e em outros lugares pobres. Ou seja: o excesso de lixo sem destinação correta acaba em lixões, que causam sérios problemas ambientais (que ocasionam problemas sociais - como a saúde pública) em países menos desenvolvidos. A África, principalmente, se tornou um grande "lixão" do resto do planeta.

Para um país alcançar desenvolvimento sustentável dentro de um contexto global, deve assegurar um padrão de vida decente e sua Pegada Ecológica per capita não deve ser maior do que a biocapacidade per capita disponível no planeta. Atualmente, nenhum país cumpre esses critérios (WWF, 2018). Os dados apresentados pelo Relatório Planeta Vivo evidenciam que hábitos de consumo individuais tem grande impacto ambiental. Isso mostra a importância da consciência e responsabilização de cada um pelo seu impacto na degradação ambiental e pela necessidade de mudanças de hábitos a fim de buscar um planeta mais sustentável. Para alcançar a sustentabilidade é imprescindível alcançar equilíbrio nos níveis globais de consumo. As diferenças entre o consumo excessivo praticado por classes privilegiadas e o consumo insuficiente a que se submetem as populações em situação de vulnerabilidade são evidenciadas a seguir.

\section{Consumo excessivo nos países privilegiados do hemisfério norte}

A abundância dos bens de consumo, continuamente produzidos pelo sistema industrial, é considerada, frequentemente, um símbolo do sucesso das economias capitalistas modernas. No entanto, esta abundância passou a receber uma conotação negativa, sendo objeto de críticas que consideram o consumismo um dos principais problemas das sociedades industriais modernas (CORTEZ, 2009). A relação entre consumo e bem estar está enraizada nos modelos econômicos tradicionais, que de acordo com Jackson (2005) tratam o consumidor como um ser de desejos insaciáveis, que sempre quer consumir mais para sentir-se em uma situação mais favorável.

O excesso de consumo não estaria relacionado com a satisfação de necessidades do ser humano, que segundo Czinkota et al (2001), são condições insatisfatórias - relacionadas a exigências humanas básicas, como comer, respirar, abrigar-se, divertir-se, educar-se entre outras - que levam a ações que melhorarão estas condições. O excesso estaria ligado aos desejos, que Czinkota et al (2001) conceituam como aspirações de obter mais satisfação do que o absolutamente necessário para melhorar uma condição insatisfatória. Esses desejos são influenciados por fatores socioambientais (culturais, sociais, econômicos), por isso os hábitos de consumo são tão influenciados pelo a mbiente no qual o consumidor está inserido.

À medida que a sociedade enriquece, surgem novos desejos de consumir e esses desejos se propagam nos âmbitos sociais, especialmente entre aqueles que têm condições financeiras para tal. Para o Filósofo francês Gilles Lipovetsky (2007), até 1970, isso é explicado pela lógica da diferenciação social, onde os indivíduos consumiam para ter prestígio, reconhecimento, status e integração social. Após esse período, começa a se observar o que o autor chama de uma sociedade de "hiperconsumo", na qual o consumo passa a ser algo emocional, uma forma de distração dos problemas reais, seduzindo os indivíduos. O consumo torna-se uma corrida pelo bem-estar individual e uma maneira de combater a angústia, por meio do consumo hedonista, com a busca infinda pela felicidade e a consequente sensação de desamparo, quando aquilo que se compra não mantém a sensação de conforto desejada. O indivíduo sente que precisa comprar certo produto para satisfazer um vazio emocional, e sente-se impotente diante das imposições da mídia. Lipovetsky (2007) chama essa situação de "felicidade paradoxal", pois ao buscar a felicidade por meio do consumo, o indivíduo acaba conquistando ainda mais angústias. 
os indivíduos encontram-se alienados e passivos diante das imposições da sociedade de consumo. Com isso, o autor questiona se o consumo realmente traz algum tipo de satisfação, visto que mesmo com o crescimento econômico e, consequentemente, nos níveis de consumo, o nível de satisfação de vida permaneceu praticamente inalterado nos últimos trinta anos. Além disso, o autor também aponta que as pessoas apresentam mais distúrbios psicológicos (como ansiedade) a cada década, corroborando a tese de Lipovetsky (2007) de que o consumo pode causar mais angústias que saná-las. Sanne (2005) aponta que mesmo tendo certa consciência de que mais consumo não traz mais satisfação, o consumidor sente que a insatisfação é a condição normal, logo, consome para ficar "menos insatisfeito".

Pode-se observar que o excesso de consumo está, muitas vezes, relacionado a questões como diferenciação social e busca por sanar questões emocionais, que nada tem a ver com o suprimento de necessidades. Isso causa um acúmulo de bens supérfluos que agravam a degradação do meio ambiente e podem levar o indivíduo a diversos problemas psicológicos relacionados à ansiedade ou até ao endividamento, dependendo da sua situação econômica. Em contraste a esse consumo exagerado, de acordo com o Relatório Planeta Vivo da Rede WWF (2018), quase um bilhão de pessoas passam fome, 768 milhões de pessoas não tem acesso à água limpa e segura e 1,4 bilhões de pessoas não têm acesso a fontes de energia confiá veis. Esse consumo insuficiente é discutido a seguir.

\section{CONSUMO INSUFICIENTE NA BASE DA PIRÂMIDE}

O relatório da WCED enfatiza que a redução da pobreza é condição indispensável para um desenvolvimento verdadeiramente sustentável. Ao analisar dados de consumo familiar em diferentes países, Cortez (2009) aponta que os maiores gastos nos países menos favorecidos são relacionados à alimentação. Isso não significa que essa população se alimente bem, mas demonstra que, o grande desafio é mesmo a sua sobrevivência, ou seja, a alimentação em primeiro lugar, onde não restam condições para as outras necessidades consideradas "supérfluas". Com isso fica claro que as políticas de consumo sustentável devem estar relacionadas, em primeiro lugar, com a eliminação da pobreza, ou seja, elevar o piso mínimo de consumo daqueles que vivem abaixo de um padrão de consumo que garanta uma vida digna.

O mercado consumidor chamado "base da pirâmide" é constituído, de acordo com Farias e Farias, (2010), por mais de quatro bilhões de pessoas que vivem com menos de dois dólares por dia. São os membros dos países emergentes, que estão iniciando seu processo de consumo no mundo globalizado. O consumo na base da pirâmide, como forma de superação de níveis extremos de pobreza, ganhou relevância nos estudos acadêmicos centrados especialmente em dois focos: a relevância que esses mercados ganharam para as empresas que passaram a valorizá-los como público com forte potencial de mercado; e a questão da sustentabilidade, visto que o aumento no consumo por essa grande parcela da população tende a causar graves impactos ambientais.

A base da pirâmide, por se sentir socialmente excluída, apresenta dificuldades em se inserir no mercado consumidor. Para que haja uma real inclusão, Prahalad (2012) enfatiza a importância da inovação e da adaptação dos produtos, serviços e do próprio modelo de negócios às características específicas desse público. Para o autor, a abordagem gerencial nesses mercados deve focar na criação de consciência sobre o produto (para que os consumidores tomem conhecimento dele e suas utilidades); possibilidade de acesso, mesmo em locais remotos; acessibilidade dentro das condições financeiras do público alvo; e garantia de disponibilidade no fornecimento do produto. Ele considera importante também adicionar aspectos emocionais que incorporem aspirações desse público nos produtos.

Kolk et al. (2014) ao investigar o estado da arte da pesquisa sobre a base da pirâmide, concluíram que pequenas empresas locais têm uma função essencial ao promover essas inovações e adaptações de produtos defendidas por Prahalad (2012). O aspecto mais significativo da evolução deste campo, de acordo com Kolk et al. (2014), tem sido a expansão do conceito e medição da pobreza de uma definição puramente baseada na renda para um construto multidimensional que inclui privação material, falta de educação, problemas de saúde, vulnerabilidade, falta de voz e exclusão.

É importante considerar, portanto, que uma abordagem baseada no consumo em um mercado onde as pessoas são pobres e têm pouco acesso à educação e saúde poderia apenas 
configurá-los para fins de exploração. Ao invés de tratá-los apenas como consumidores, outra abordagem trazida por autores da área é vê-los como produtores, trabalhadores e empresários. O emprego e a educação forneceriam a ajuda necessária para movê-los para fora da pobreza extrema, visto que a pobreza é um ciclo vicioso - não tendo acesso a recursos básicos, as pessoas são forçadas a gastar a maior parte de seu tempo em empregos de baixo nível, a fim sobreviver a cada dia, o que diminui o acesso a estudo e qualificação, que lhes permitam sair da armadilha da pobreza. Esta falta de oportunidades os aprisiona em situação de pobreza, mesmo em tempos de crescimento econômico (FARIAS e FARIAS, 2010).

É preciso tomar cuidado também para que a fuga do ciclo da pobreza não faça que a pessoa caia em outro ciclo vicioso: o do consumo. Há uma relação direta no aumento da renda com o aumento do consumo e isso muitas vezes leva ao consumo desnecessário e indesejado, resultando em desperdício e poluição. Com a rápida inovação tecnológica e a obsolescência planejada de produtos, há um incentivo contínuo para comprar novos modelos. Isso pode trazer benefícios de crescimento econômico a curto prazo para o mercado, mas tem o potencial para o desastre ambiental a nível global a longo prazo (FARIAS e FARIAS, 2010).

O Capítulo 4 da Agenda 21 aponta que em seu processo de desenvolvimento, os países em desenvolvimento devem procurar atingir padrões sustentáveis de consumo, garantindo o atendimento das necessidades básicas dos pobres e, ao mesmo tempo, evitando padrões insustentáveis, especialmente os dos países industrializados, geralmente considerados especialmente nocivos ao meio ambiente, ineficazes e dispendiosos. Isso exige um reforço do apoio tecnológico e de outras formas de assistência por parte dos países industrializados.

O consumo na base da pirâmide deve ter o foco na superação das condições de pobreza e na busca de condições dignas de subsistência. A partir disso, o foco deve ser voltado para a educação, para que as pessoas tenham condições de buscar melhores condições e oportunidades futuras para si, além de conseguirem esclarecimento sobre as consequências do consumo excessivo e evitem as armadilhas do consumismo. A seguir, diferentes focos sobre o consumo são discutidos.

\section{CONSUMO VERDE, CONSUMO CONSCIENTE OU CONSUMO SUSTENTÁVEL?}

A partir da percepção de que os atuais padrões de consumo estão nas raízes da crise ambiental, ficando cada vez mais claro que estilos de vida diferentes contribuem de formas diferentes para a degradação ambiental, movimentos em busca de padrões de consumo mais sustentáveis começam a se fortalecer. O consumidor passa a questionar qual o papel dos diferentes atores na busca de soluções para os problemas ambientais, posicionando-se e cobrando atitudes, assim como passa também a assumir a sua própria responsabilidade. Com isso surge uma série de posturas, como "consumo verde", "consumo responsável/consciente/ético" e “consumo sustentável” (CORTEZ, 2009).

Os conceitos de diferentes termos relacionados a novos hábitos de consumo que estariam mais alinhados aos preceitos do desenvolvimento sustentável muitas vezes são confundidos ou até mesmo utilizados como sinônimos na literatura, sem especificar uma diferenciação clara entre eles. Para esse estudo buscou-se um significado mais profundo para cada termo, a fim de compreender melhor a evolução do pensamento social relacionado aos hábitos de consumo e o papel do consumidor nesse processo.

\section{Consumo Verde}

Segundo Neves (2000), no imaginário popular, as empresas só pensam em lucro, enganam os consumidores, exploram os empregados, sonegam impostos, corrompem autoridades, poluem o ambiente, são insensíveis aos problemas sociais e comandam ou participam de grandes conspirações contra a humanidade. Nesse contexto, pode-se interpretar que o pensamento coletivo popular tende a culpar as grandes corporações pela degradação ambiental do planeta. Elas seriam as maiores poluidoras, com seus métodos de produção que exploram os recursos naturais e emitem gases tóxicos, além de incentivarem os hábitos insustentáveis de consumo por meio da publicidade massiva dos seus produtos. Nessa visão mais tradicional, o consumidor espera que o governo imponha limites para as empresas e que elas próprias tomem atitudes proativas para reverter os problemas que causam e busquem 
novos meios de produção menos agressivos. Tachizawa (2007) defende por meio de estudos realizados entre consumidores, que a maior parte dos pesquisados estaria disposto a pagar mais por um produto que não agredisse o meio ambiente. $\mathrm{O}$ consumidor, portanto, privilegiaria no momento de sua escolha as empresas que utilizam métodos mais ecologicamente corretos e produzam itens com materiais renováveis e mais naturais - produtos "verdes".

O consumo verde está relacionado com as mudanças tecnológicas para melhorar o desempenho ambiental de um produto (CORTEZ, 2009). Para se adaptar a esse cenário, muitas empresas estão implantando sistemas de gerenciamento ambiental a fim de reduzir custos e riscos com multas e indenizações, minimizar desperdícios, aumentar a eficiência dos recursos, tornarem-se mais produtivas e melhorar sua imagem diante de um consumidor mais crítico e exigente - o "consumidor verde". Elas adotam essa postura pensando não apenas no bem comum, mas em uma lógica de negócios, de como podem se adaptar e se tornar mais lucrativas nessa realidade.

As atividades desenvolvidas pelas empresas ao longo de sua cadeia de suprimentos tendem a ocasionar sérios impactos ao ambiente, como o desperdício dos recursos naturais e as emissões de gases nocivos. Com a crescente preocupação ambiental, essas atividades se tornaram um dos focos de mudança, ocasionando o surgimento do conceito de Green Supply Chain Management (GSCM) - ou Gestão da Cadeia de Suprimentos Verde. Ela pode ser conceituada como a integração ambiental na cadeia de suprimentos, incluindo a concepção do produto, a procura e a seleção de material, os processos de fabricação, a entrega do produ to final aos consumidores e a gestão do produto após o término do seu ciclo de vida (SRIVASTAVA, 2007).

Para Srivastava (2007), a GSCM tem como objetivo reduzir a carga ecológica, utilizando materiais e tecnologias apropriadas, minimizando desperdícios e auxiliando a economia de custos. Alves e Nascimento (2014) apontam que GSCM engloba atividades de redução de perdas, reciclagem, desenvolvimento de fornecedores, desempenho dos compradores, compartilhamento de recompensas e riscos, adoção de tecnologias mais limpas, adequações a normas e legislação, reutilização de materiais, economia no consu mo de água e de energia, utilização de insumos ecologicamente corretos e processos de produção mais enxutos e flexíveis. Essas atividades devem ser de responsabilidade de todos os participantes da cadeia.

Além do fluxo direto da cadeia produtiva, é importante também a preocupação com o fluxo de retorno dos resíduos deixados por um produto após seu uso para que tenham a destinação adequada - a chamada logística reversa. De acordo com Corrêa e Xavier (2013), a logística reversa envolve o transporte e a gestão apropriada dos resíduos: o descarte final da forma que cause menos danos ao meio ambiente, ou, sempre que possível, a reutilização, reciclagem, renovação e reinserção de materiais de volta nas cadeias de suprimentos. Nesse contexto, cresce o conceito de "economia circular", na qual a fim de não aumentar o consumo de recursos, é priorizado o reaproveitamento de resíduos da cadeia produtiva. A economia circular, de acordo com Ghisellini et al. (2016), visa a aumentar a eficiência do uso de recursos, com foco especial em resíduos urbanos e industriais, para alcançar um melhor equilíbrio e harmonia entre economia, meio ambiente e sociedade.

Além do processo produtivo, o próprio produto deve buscar um desempenho ambiental superior, por meio de inovações tecnológicas. Para Hansen e Große-Dunker (2012) inovação orientada para a sustentabilidade consiste na introdução comercial de um produto ou serviço que comparativamente com sua versão anterior leve a um benefício ambiental e/ou social ao longo do seu ciclo de vida, de forma rastreável (qualitativa ou quantitativamente). Nidumolu, Prahalad e Rangaswami (2009) consideram que a sustentabilidade é agora o principal motor da inovação. Para os autores, as empresas devem visualizar o cumprimento de normas e conformidade com a legislação ambiental como uma oportunidade e um incentivo para o uso de novas tecnologias voltadas para a sustentabilidade. Para isso, devem tornar suas cadeias de suprimento sustentáveis, incentivando a inovação no desenvolvimento de fontes sustentáveis de matérias-primas e componentes; e desenvolver produtos e serviços sustentáveis ou redesenhar os já existentes para se tornarem eco-amigáveis.

Pode-se observar que essa "tendência verde" não é proveniente apenas de "boas intenções" de empresários com o meio ambiente. Ela é baseada na necessidade de sustentação financeira da empresa a longo prazo em um canário no qual as legislações são mais rigorosas 
e existem casos de empresas que tiveram sua imagem prejudicada diante do público ao serem expostas por conta de impactos ambientais em suas cadeias. O raciocínio básico é que os investimentos na cadeia verde podem ser traduzidos em economia de recursos, eliminação de desperdícios e melhoria de produtividade. É novo enfoque à responsabilidade das empresas com o meio ambiente, envolvendo um relacionamento compartilhado com fornecedores, órgãos governamentais, organizações não governamentais, consumidores e sociedade em geral.

Cortez (2009) aponta que apesar dos seus benefícios, a estratégia de consumo verde tem algumas limitações, como o estímulo ao consumo desses produtos por meio de ações de marketing ecológico, o que proporcionaria apenas uma troca de marca, fazendo com que o consumidor tenha uma percepção de que suas escolhas melhoraram, mas não há uma efetiva redução nos hábitos de consumo. De acordo com a autora, muitas empresas passaram a focar o poder de compra de pessoas com alto poder aquisitivo interessadas em um estilo de vida de baixo impacto ambiental, percebendo-as como um novo nicho de mercado. Dessa maneira, a necessidade de redução e modificação dos padrões de consumo foi substituída pelo simples "esverdeamento" dos produtos e serviços. Outra limitação importante destacada por Cortez (2009) é que o consumo verde enfrentaria apenas uma parte do problema - a tecnologia -, enfatizando o desenvolvimento de produtos verdes para uma parcela da sociedade, enquanto a parcela mais desfavorecida (a base da pirâmide) continua tendo acesso a produtos inferiores e com um nível de consumo abaixo da satisfação de suas necessidades básicas.

\section{Consumo sustentável}

A continuidade da crise ambiental e a imensa desigualdade nos níveis de consumo entre pessoas de diferentes regiões e classes sociais evidenciou a necessidade de ir além da simples substituição por marcas "verdes" e da escolha por empresas com atuação socioambiental ética. É preciso buscar a ações coletivas que interliguem o papel das empresas (com produtos de superior desempenho ambiental, cadeias produtivas limpas, atuação ética e programas de desenvolvimento social); dos governos (com legislações rígidas em relação à exploração ambiental, políticas públicas efetivas para que a base da pirâmide tenha um nível de consumo digno e educação ambiental para conscientização de toda a população em relação à necessidade de equilíbrio nos níveis de consumo); e os próprios consumidores (que a partir da educação ambiental tenham consciência do seu papel e da sua responsabilidade).

Cortez (2009) aponta que o consumo sustentável tem uma proposta mais ampla que as estratégias anteriores, pois, além das inovações tecnológicas e das mudanças nas escolhas individuais de consumo, enfatiza ações coletivas e mudanças políticas, econômicas e institucionais para fazer com que os padrões e os níveis de consumo se tornem mais sustentáveis. A preocupação se transfere da tecnologia dos produtos e serviços e do comportamento individual para os níveis de consumo desiguais. É preciso considerar que o meio ambiente não está relacionado apenas a uma questão de como os recursos são usados (padrões), mas também a uma preocupação com o quanto são utilizados (níveis), tornando-se uma questão de acesso, distribuição e justiça social e ambiental. Conclui-se que mais importante que o impacto social e ambiental da distribuição desigual do acesso aos recursos naturais é o próprio impacto ambiental do consumo: tanto o "subconsumo" quanto o "superconsumo" causam degradação social e ambiental.

A Carta da Terra (2000) apresenta alguns princípios na busca de uma sociedade global mais justa e sustentável. Esses princípios podem ser relacionados às estratégias de mudanças de hábitos de consumo, como o "respeito e cuidado com a comunidade e com a vida" e a "integridade ecológica". O terceiro princípio apresentado pode ser especialmente associado ao consumo sustentável ao apontar a importância da busca por "justiça social e econômica". Ele busca a erradicação da pobreza, por meio do acesso a recursos básicos a todos; o desenvolvimento humano de forma equitativa e sustentável, com a distribuição equitativa de riquezas, recursos intelectuais e oportunidades, acesso universal à educação, assistência de saúde e às oportunidades econômicas; entre outras ações que bu scam colaborar com uma vida digna a pessoas desfavorecidas e minorias.

Os atuais níveis de consumo por parte do mundo desenvolvido não são sustentáveis, causando enorme devastação ambiental ao planeta e quando os países pobres do mundo começam a consumir mais para manter um padrão de vida razoável essa situação torna-se 
ainda mais preocupante. Farias e Farias (2010) apontam que deve haver limites para o crescimento econômico - o que precisa ser parte de qualquer discussão para solução da pobreza. Esses limites devem vir tanto dos países desenvolvidos quanto dos emergentes. Um exemplo é a revisão do Protocolo de Kyoto, no qual não se esperava que países emergentes limitassem seu crescimento com a redução de emissões de carbono que foi imposta aos países desenvolvidos. O mundo desenvolvido também precisa rever seus padrões de con sumo, sendo essencial a redução de desperdícios, deixando espaço ambiental para as economias emergentes crescerem.

\section{Entendendo as diferenças}

A fim de ilustrar as diferenças entre as três estratégias de mudanças de hábitos de consumo, Cortez (2009) traz o exemplo da área de transportes, conforme a Figura 1 . Na estratégia de consumo verde, haveria mudanças tecnológicas para que os carros se tornassem mais eficientes (consumindo menos combustível) e menos poluentes. No consumo consciente haveria mudanças comportamentais dos consumidores, que considerariam essas informações sobre o produto além de buscar dados relevantes sobre a empresa fabricante na hora da compra de um automóvel. Na estratégia do consumo sustentável, haveria também investimentos em políticas públicas visando a melhoria dos transportes coletivos, o incentivo aos consumidores para que utilizem esses transportes e o desestímulo para que não utilizem o transporte individual.

Figura 2: exemplo das estratégias de mudanças de hábitos de consumo - transporte

Consumo verde

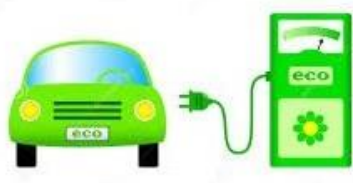

Consumo consciente

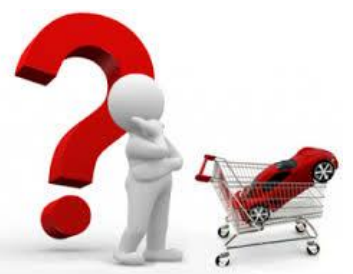

Consumo sustentável

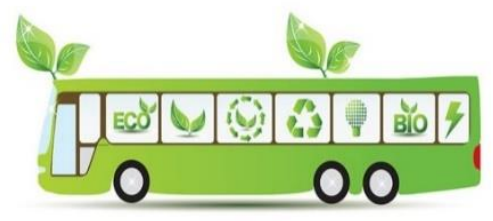

Fonte: elaborado pelos autores. Adaptado de Cortez (2009)

Outro exemplo no qual podemos refletir sobre as diferentes estratégias de consumo é no setor de alimentação. Um consumidor verde poderia optar por produtos com selos de qualidade como o de alimentos orgânicos, ou ainda consumir produtos que optem por embalagens feitas de materiais reciclados. No consumo consciente haveria a reflexão por parte do consumidor das suas escolhas alimentares, como, por exemplo, reduzir o consumo de carne, visto que a pecuária é a atividade econômica que mais causa danos ao meio a mbiente (IATP, 2018). Já no consumo sustentável, além de fazer escolhas mais responsáveis como as citadas anteriormente, o consumidor se preocuparia com a origem do seu alimento, dando preferência a produtores locais, agricultores familiares e demais fornecedores que incentivem o desenvolvimento social e econômico da sua comunidade. 


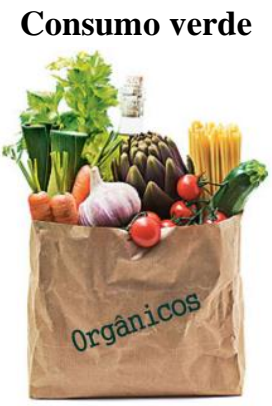

Consumo consciente

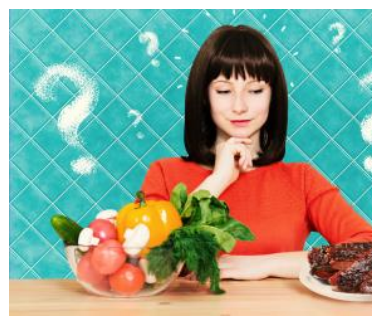

Consumo sustentável

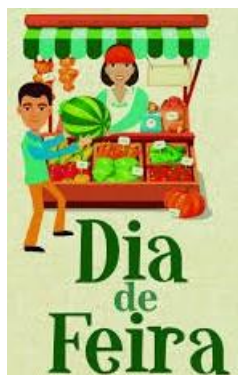

Fonte: elaborado pelos autores.

As estratégias de consumo sustentável, entretanto, ainda encontram muita resistência na sociedade. Níveis equilibrados de consumo implicam em uma mudança drástica nos hábitos das populações mais favorecidas e isso parece uma realidade distante. Silva e Shimbo (2004) apontam que experiências inovadoras nas políticas públicas voltadas para a melhor distribuição de recursos têm se confrontado com interesses conservadores que buscam firmar seus privilégios frente à coletividade. Pode-se compreender que enquanto o pensamento individualista continuar a se sobrepor ao pensamento coletivo, a estratégia de consumo sustentável pode parecer algo utópico.

Para sistematizar os temas abordados nesse estudo, o seguinte modelo analítico, na figura 4, foi realizado para resumir a realidade atual descrita e aquilo que se busca alcançar com as mudanças nos padrões de consumo.

Figura 4: modelo analítico resumindo os temas abordados

\section{Situação atual}

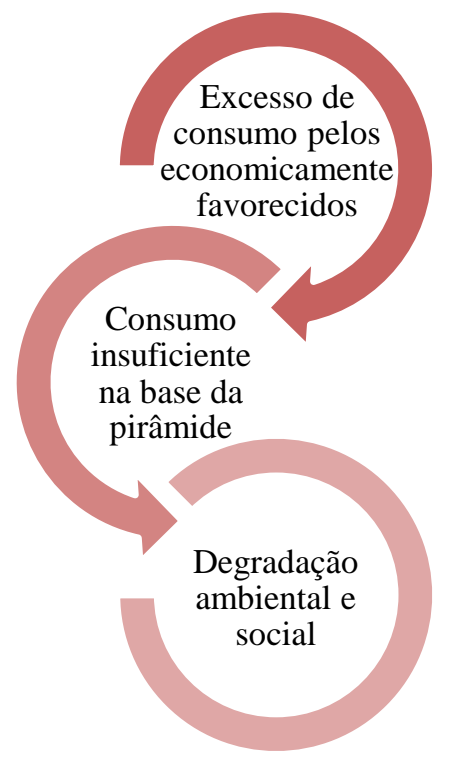

\section{Situação desejada}

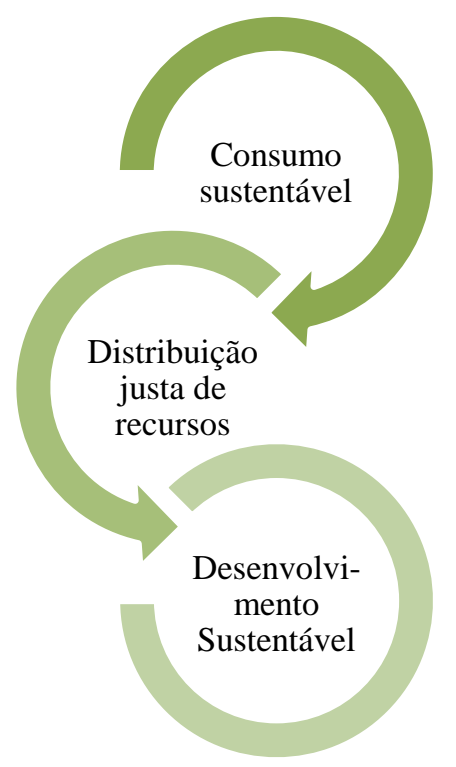

Fonte: elaborada pelos autores.

\section{CONSIDERAÇÕES FINAIS}

A revisão da bibliografia sobre os temas abordados e o levantamento de dados por meio da análise de relatórios de órgãos especializados indicam que há vínculos entre os níveis desequilibrados de consumo dos países ricos em relação aos países em desenvolvimento, com 
os processos de degradação ambiental e social. A reflexão sobre os hábitos individuais e as suas consequências é uma necessidade iminente entre as populações mais favorecidas, cujo acesso aos recursos é facilitado. A pobreza e as condições miseráveis às quais outras pessoas são submetidas, que parecem tão distantes a essas populações privilegiadas, devem ser compreendidas por tais como uma consequência direta dos excessos que fazem parte de sua rotina e muitas vezes nem são percebidos.

Tal reflexão foi ao encontro do objetivo central do estudo de debater os dados relacionados aos hábitos de consumo excessivos praticados por populações economicamente favorecidas, em contraste com o consumo insuficiente ao qual grande parte da população mundial é submetida devido à falta de acesso aos recursos. Para enfrentar o problema, o estudo apresentou possíveis estratégias de mudanças nos padrões de consumo, especialmente destinadas às populações que consomem de forma excessiva e devem repensar seus hábitos, a fim de proporcionar economia nos recursos utilizados, com menor degradação ambiental.

Quando se trata desse tema, confrontam-se diretamente os interesses dos grandes detentores de capital. As empresas tradicionais, com orientação principal focada ao lucro, não têm interesse que as pessoas reduzam os seus hábitos de consumo, pois a diminuição no volume de vendas tende a reduzir a sua receita. Para que as pessoas continuem consumindo, mas tenham a impressão de estar contribuindo para o desenvolvimento sustentável, as empresas desenvolvem produtos com melhor desempenho ambiental e os promove como sendo "ecológicos", por meio de estratégias de "marketing verde". Com isso, vendem a ideia de que as pessoas não precisam consumir menos, apenas consumir "melhor", ou seja, selecionar a sua marca.

Mesmo que a sua marca seja verdadeiramente melhor para o meio ambiente e as pessoas, esses produtos dificilmente são disponíveis para os consumidores da base da pirâmide - aqueles que mais precisam de melhoria de qualidade em seu consumo. Logo, as abordagens tradicionais de negócio tendem a entrar em colapso, e as empresas terão de desenvolver soluções inovadoras que busquem a sustentabilidade. Esse é um processo de aprendizagem que envolve uma cultura organizacional voltada para a inovação.

A mudança na tecnologia dos produtos é, sem dúvidas, um grande avanço rumo a um mundo mais sustentável, mas esses produtos também exigem a exploração de recursos, logo não podem ser consumidos indiscriminadamente em quantidades excessivas. Além do esgotamento de recursos, o excesso de consumo também ocasiona o problema do excesso de lixo, que em casos como o do lixo eletrônico, por exemplo, acabam sendo destinados a lixões em países mais pobres, ocasionando uma série de outros problemas ambientais e sociais nesses locais.

O consumidor verdadeiramente consciente é aquele que incorpora os princípios da sustentabilidade e inclui em suas decisões de consumo não apenas informações sobre o que é consumido, mas sobre o impacto que aquele consumo traz para o planeta e para os demais habitantes deste. Apesar da importância de o consumidor assumir a sua responsabilidade, ele jamais pode abster-se de pensamento crítico e permitir que outros atores deixem de assumir o seu próprio papel. Cortez (2009) afirma que frequentemente, governos e empresas buscam suavizar sua responsabilidade, transferindo-a para o consumidor, que passou a ser considerado o principal responsável pela busca de soluções. A responsabilidade deve ser compartilhada por todos, em cada esfera de ação. O destaque na mudança dos padrões de consumo deve ser visto como uma forma de fortalecer a ação política dos cidadãos, que além de assumir o seu papel sabe cobrar dos demais atores as suas devidas atribuições.

Para alcançar esse nível de esclarecimento é preciso que o consumidor seja apropriadamente informado sobre as questões que pautam o Desenvolvimento Sustentável. Para Cars e West (2014), a educação é um componente social indispensável e uma ferramenta poderosa para o desenvolvimento de uma sociedade pacífica e sustentável. O Desenvolvimento Sustentável exige mudanças de atitudes e valores nas pessoas, e a educação é a chave. A educação voltada para a sustentabilidade deve incluir temas como as alterações climáticas, riscos de desastres, biodiversidade, redução da pobreza e consumo sustentável. Exige também o uso de métodos participativos, que capacitem, promovam competências e pensamento crítico voltado para a coletividade, além de motivar o indivíduo a mudanças de comportamento.

É preciso que as pessoas sejam críticas consigo mesmas ao avaliarem o impacto negativo 
que podem causar e façam escolhas e sacrifícios visando às necessidades de todos, não somente as de si próprio. Moderação no consumo considerando a qualidade de vida dos outros é fundamental (FARIAS e FARIAS, 2010). Esse tipo de consciência apontada pelos autores é algo que também pode ser desenvolvido por meio da educação, mas que é principalmente adquirido por meio das interações sociais, por isso é importante evidenciar também o papel da família e demais grupos de referência na formação dos hábitos de consumo das pessoas. Para isso, é necessário desenvolver processos de aprendizagem social voltados à educação das pessoas em função da sustentabilidade, deixando o pensamento individualista e focando no pensamento global, visando o bem-estar das demais pessoas e do meio ambiente, e possibilitando, com isso, perspectivas de observar resultados efetivos na busca por Desenvolvimento Sustentável.

O consumo sustentável, muito mais que a simples escolha por marcas consideradas mais alinhadas aos preceitos ecológicos, consiste em uma mudança de hábitos que inclua o pensamento coletivo nas decisões individuais. Tal diferenciação e esclarecimento quanto às estratégias voltadas às mudanças nos hábitos de consumo atende ao segundo objetivo traçado pelo estudo, evidenciando o papel de cada ator no processo. Para estudos futuros relacionados ao tema, sugere-se a identificação de situações práticas nas quais possam ser visualizadas as estratégias (ver Figuras 2 e 3) de consumo verde, consciente e sustentável e suas diferentes aplicações e resultados em países desenvolvidos do hemisfério norte e subdesenvolvidos do hemisfério sul - uma limitação desse estudo que se deteve na discussão em âmbito teórico.

\section{Referências}

AGENDA 21. Conferência das Nações Unidas sobre Meio Ambiente e Desenvolvimento. Capítulo 4: mudança dos padrões de consumo. Disponível em <http://www.mma.gov.br/responsabilidadesocioambiental/agenda-21>. Acesso em 13 nov. 2018.

ALVES, A. P. F.; NASCIMENTO, L. F. M. (2014). Green Supply Chain: protagonista ou coadjuvante no Brasil? RAE - Revista de Administração de Empresas. Vol. 54, no 5, p. 510-520, 2014.

BARBIERI, J. C.; SILVA, D. Desenvolvimento sustentável e educação ambiental: uma trajetória comum com muitos desafios. RAM - Revista de Administração Mackenzie, Vol. 12, nº. 3, Edição Especial. São Paulo, SP. Maio/Jun, 2011.

BATEMAN, T. S., SNELL, S. A. Administração: construindo vantagem competitiva. São Paulo: Atlas, 1998.

CARS, M.; WEST, E. E. Education for sustainable society: attainments and good practices in Sweden during the United Nations Decade for Education for Sustainable Development (UNDESD). Environment, Development and Sustainability. Vol. 17, nº 1, p. 1-21, 2014.

CARTA DA TERRA, 2000. Ministério do Meio Ambiente. Agenda 21. Carta da Terra. Disponível em: $<$ http://mma.gov.br/responsabilidade-socioambiental/agenda-21/carta-da-terra>. Acesso em 13 nov 2018.

CASTRO, A. E.; CAMPOS, S. A. P.; TREVISAN, M. A institucionalização (ou banalização) da Sustentabilidade Organizacional à luz da teoria crítica. Revista do Pensamento Contemporâneo em Administração. Rio de Janeiro, v. 12, n. 3, jul./set. 2018, p. 110-123.

CDIAC. Ranking of the world's countries by 2014 total CO2 emissions. Disponível em <http://cdiac.ornl.gov/trends/emis/meth_reg.html\#>. Acesso em 13 nov 2018.

CHENG, X.; SHUAI, C.; LIU, J; WANG, J; LIU, Y; LI, W; SHUAI, J. Topic modelling of ecology, environment and poverty nexus: An integrated framework. Agriculture, Ecosystems \& Environment. Volume 267, 15 November 2018, Pages 1-14.

CORRÊA, H.L., XAVIER, L. H. Concepts, design and implementation of Reverse Logistics Systems for sustainable supply chains in Brazil. Journal of Operations and Supply Chain Management. Vol. $6, \mathrm{n}^{\mathrm{o}}, 1$, p. 1-25, 2013.

CORTEZ, A. T. C.. Consumo e Desperdício: as duas faces das desigualdades. In: ; ORTIGOZA, S.A.G. (Orgs). Da Produção ao Consumo: Impactos Sócio-Ambientais no Espaço Urbano. 1ed. São Paulo: Cultura Acadêmica, 2009, v. 1, p. 35-62.

CUSHING, L.; MORELLO-FROSCH, R.; WANDER, M.; PASTOR, M. The haves, the have-nots, and the health of everyone: the relationship between social inequality and environmental quality. Annual Review of Public Health. 2015 Mar 18;36:193-209. DOI: 10.1146/annurev-publhealth-031914- 
122646 .

CZINKOTA, M. R. et al. Marketing: as melhores práticas. Porto Alegre: Bookman, 2001.

DIAS, R.; ZAVAGLIA, T.; CASSAR, M. Introdução à administração: da competitividade à sustentabilidade. Campinas: Editora Alínea, 2003.

ELKINGTON, J. Sustentabilidade: canibais de garfo e faca. São Paulo: M. Books do Brasil Editora Ltda. 2012.

FARIAS, C.; FARIAS, G. Cycles of poverty and consumption: the sustainability dilemma, Competitiveness Review: An International Business Journal, Vol. 20 n: 3, p. 248-257, 2010.

GHISELLINI, P.; CIALANI, C.; ULGIATI, S. A review on circular economy: the expected transition to a balanced interplay of environmental and economic systems. Journal of Cleaner Production. Volume 114, p. 11-32, feb 2016. DOI: 10.1016/j.jclepro.2015.09.007

GLAVIČ, P., LUCKMAN, R. Review of sustainability terms and their definitions, Journal of Cleaner Production, Vol. 15, $\mathrm{n}^{\circ}$. 18, p. 1875-1885, 2007.

GRACIOSO, F. Propaganda institucional: nova arma estratégica da empresa. $2^{\text {a }}$ Ed. São Paulo: Atlas, 2006.

GRANT, R.; OTENG-ABABIO, M. Mapping the invisible and real "african" economy: urban ewaste circuitry. Urban Geography. Volume: 33, Ed. 1, p. 1-21, jan-feb 2012. DOI: 10.2747/02723638.33.1.1

HANSEN, E. G.; GROßE-DUNKER, F. Sustainability-Oriented Innovation. In S. O. Idowu, N. Capaldi, L. Zu, \& A. Das Gupta (Eds.), Encyclopedia of Corporate Social Responsibility. Vol. 1, p. 24072417. Heidelberg, New York: Springer-Verlag, 2013.

HUMBERG, M. E. O profissional e a ética empresarial. In: KUNSCH M. M. K. (Org.). Obtendo resultados com Relações Públicas. $2^{a}$ Ed. São Paulo: Pioneira Thomson Learning, 2006. Cap. 6, p. 81-88.

IATP - Institute for Agriculture and Trade Policy. Emissions impossible: How big meat and dairy are heating up the planet. 18 Jul 2018. Disponível em <https:/www.grain.org/article/entries/5976emissions-impossible-how-big-meat-and-dairy-are-heating-up-the-planet>. Acesso em 26 ago 2019.

JACKSON, T. Live Better by Consuming Less? Is There a "Double Dividend" in Sustainable Consumption? Journal of Industrial Ecology. Vol. 9, n 1-2, p. 19-36, 2005.

KOLK, A. The social responsibility of international business: From ethics and the environment to CSR and sustainable development. Journal of World Business. Volume 51, Issue 1, January 2016 , Pages 23-34. doi: https://doi.org/10.1016/j.jwb.2015.08.010

KOLK, A.; RIVERA-SANTOS, M.;RUFIN, C. Reviewing a Decade of Research on the "Base/Bottom of the Pyramid" (BOP) Concept. Journal of Business Venturing. Volume 30, Issue 3, May 2015, Pages 436-451. doi: 10.1177/0007650312474928

KOTLER, P.; KELLER, K. L. Administração de marketing. 12a Ed. São Paulo: Prentice Hall, 2007.

LEAL FILHO, W.; ULISSES, A.; ALVES, F.; PACE, P.; MIFSUD, M.; BRANDLI, L.; CAEIRO, S. S.; DISTERHEFT, A. (2017): Reinvigorating the sustainable development research agenda: the role of the sustainable development goals (SDG), International Journal of Sustainable Development \& World Ecology, DOI: 10.1080/13504509.2017.1342103

LÉLÉ, S. M. 1991. Sustainable Development: A Critical Review. World Development, Vol. 19, nº 6: p. 607-621, 1991.

LIPOVETSKY, G. A felicidade paradoxal: ensaio sobre a sociedade de hiperconsumo. São Paulo, Companhia das Letras, 2007.

MARCONI, M. A.; LAKATOS, E. M. Fundamentos de Metodologia Científica. São Paulo: Atlas S.A., 8. ed. 2017.

MMA - Ministério do Meio Ambiente/ MEC - Ministério da Educação/ IDEC - Instituto Brasileiro de Defesa do Consumidor. Consumo Sustentável: Manual de educação. Brasília: Consumers International, 160 p., 2005. Disponível em <http://portal.mec.gov.br/dmdocuments/publicacao8.pdf>. Acesso em 13 nov 2018.

MOREIRA, J. M. A ética empresarial no Brasil. São Paulo: Pioneira, 1999.

MORSE, T. D.; MASUKU, H.; RIPPON, S.; KUBWALO, H. Achieving an Integrated Approach to Food Safety and Hygiene - Meeting the Sustainable Development Goals in Sub-Saharan Africa. 
Sustainability. 2018, 10(7), 2394; doi:10.3390/su10072394

NEVES, R. C. Comunicação empresarial integrada. $2^{a}$ Ed. Rio de Janeiro: Mauad, 2000.

NIDUMOLU, R., PRAHALAD, C. K., RANGASWAMI, M. R. Why sustainability is now a key driver of innovation. Harvard Business Review. Vol. 87, nº 9: p. 57-64, 2009.

ONU. Organização das Nações Unidas. Agenda 2030 para o Desenvolvimento Sustentável. Disponível em <https://nacoesunidas.org/pos2015/agenda2030/>. Acesso em 13 nov 2018.

PNUD - Programa das Nações Unidas para o Desenvolvimento (United Nations Development Programme - UNDP). Human Development Report 2016. Disponível em $<$ http://hdr.undp.org/sites/default/files/2016_human_development_report.pdf $>$. Acesso em 13 nov 2018.

PRAHALAD, C. K. Bottom of the Pyramid as a Source of Breakthrough Innovations. Journal of Product Innovation Management. Vol. 29, nº 1, p. 6-12, 2012.

PORTILHO, F. Consumo sustentável: limites e possibilidades de ambientalização e politização das práticas de consumo. Cadernos EBAPE.BR (FGV), v. III, p. 1-12, 2005.

ROBINSON, J. Squaring the circle? Some thoughts on the idea of sustainable development. Ecological Economics, v. 48, n. 4, p. 369-384, 2004.

ROMEIRO, A. R. Economia ou economia política da sustentabilidade. In: MAY, P. H.; LUSTOSA, M. C.; VINHA, V. (Orgs.) Economia do meio ambiente: teoria e prática. Rio de Janeiro: Elsevier, 2003. P. $1-29$.

SANNE, C. The Consumption of our Discontent. Business Strategy \& the Environment. Vol. 14, p. 315-323. 2005.

SCHULTZ-PEREIRA, J. C., GUIMARÃES, R. D. Consciência Verde: uma avaliação das práticas ambientais. REGES - Revista Eletrônica de Gestão, Picos, v. 2, n. 1, p. 61-73, jan./abr. 2009.

SILVA, M. R. ; SHIMBO, I. . A dimensão política da sustentabilidade na formulação de políticas públicas de habitação. Caso: Itararé-SP e região. In: II Encontro da Associação Nacional de Pós-Graduação e Pesquisa em Ambiente e Sociedade, 2004, Indaiatuba (SP). Anais do II Encontro da Associação Nacional de Pós-Graduação e Pesquisa em Ambiente e Sociedade, 2004.

SRIVASTAVA, S. K. (2007). Green supply-chain management: a state-of the-art literature review. International Journal of Management Reviews, Vol. 9, nº 1, p. 53-80, 2007.

TACHIZAWA, T. Gestão ambiental e responsabilidade social corporativa. $4^{\mathrm{a}}$ Ed. São Paulo: Atlas S.A., 2007.

WWF BRASIL. Living Planet Report $2018 . \quad$ Disponível em $<$ https://www.wwf.org.br/natureza_brasileira/especiais/relatorio_planeta_vivo_2018/>. Acesso em 14 nov 2018. 